\title{
Problems in calibrating the heat pulse method for measuring sap flow in the stem of trees and herbaceous plants
}

\author{
Y. Cohen and M. Fuchs \\ Volcani Center Bet Dagan, P 06 Israël
}

(received 4-5-1988, accepted 14-1-1989)

\begin{abstract}
Summary - The use of heat as a tracer of sap flow in plants has aroused considerable interest because it provides the means of measuring water uptake by plants under field conditions. The heat pulse method, based on the solution of the convective heat flow equation in a homogeneous medium, can be used to determine heat velocity in plant stems. However, heterogeneity, whether natural or caused by implantation of the sensors in the conducting tissue, results in a measured heat velocity which is always lower than the actual velocity. Therefore, translating the heat velocity into a transpirational flux requires either an experimental calibration procedure or a computational correction of the flow equation. In some cases the calibration procedure is unavoidable. Calibration for several species of trees in lysimeters and on sections of branches in the laboratory produced the same calibration factor, 0.55 . Transpirational flux in trees is computed from measured heat velocity, wood physical properties, and the area of water-conducting annulus of stem. In herbaceous plants, however, uncertainties about the water-conducting stem area and its physical properties make it necessary to calibrate for each species. The tests showed that the technique can be calibrated for cotton and soybean. The method produces erratic results with tomato, and its performance with corn has not yet been established.
\end{abstract}

transpiration - xylem - cotton - corn - soybean - citrus - palm - tomato

Résumé - Problèmes d'étalonnage de la méthode du choc thermique pour la mesure du courant de sève dans la tige des arbres et des plantes herbacées. L'utilisation de la chaleur pour marquer le courant de sève dans les plantes suscite un intérêt considérable parce qu'elle permet de mesurer au champ le prélèvement de l'eau par les plantes. La méthode du choc thermique suppose que la solution de l'équation du flux de chaleur convective en milieu homogène est applicable dans la tige des plantes. Toutefois, l'hétérogénéité naturelle et celle causée par l'implantation des capteurs dans les tissus conducteurs engendre une mesure qui est moindre que la vitesse réelle du courant de chaleur. C'est pourquoi la conversion du flux de chaleur en flux de sève oblige soit à un étalonnage, soit à une solution numérique de l'équation de transport de chaleur. La discussion montre que dans certains cas l'étalonnage est inévitable. L'étalonnage d'arbres en lysimètre ou sur des branches sectionnées en laboratoire montre que la sous-estimation du flux de sève est la même pour toutes les espèces étudiées. La transpiration est calculée à partir de la vitesse de flux de chaleur en tenant compte des propriétés thermiques du bois et de la surface d'aubier actif. Dans les espèces herbacées, le manque d'informations à propos de leurs propriétés thermiques et l'indétermination de la surface active oblige à répéter un étalonnage pour chaque espèce. Les essais montrent que la méthode donne de bons résultats pour le cotonnier et le soja. Elle est erratique pour la tomate, et son utilisation pour le maïs est encore incertaine.

transpiration - cotonnier - maïs - soja - oranger - palmier - tomate

\section{Introduction}

The heat pulse method, based on heat transport theory, underestimates convective heat velocity in the conductive tissues of plants because of contact resistance between the thermometers and the medium. This discrepancy must be evaluated to determine transpiration from heat velocity in the stem. Swanson \& Whitfield (1981) corrected the numerical solution of the heat flow equation by considering the size of wounds caused by the sensors, taking into account the inter- 
ruption of flow and the modification of thermal properties. However, their approach neglects the possible effect of the water transport system's structure on the deviation of measured from true velocity.

The alternative approach is to calibrate the technique and to determine an empirical correction factor. The same factor was found for mature citrus trees and several forest trees (Cohen et al., $1981,1985)$. However, preliminary measurements in palm trees, where the conducting tissues have a low density distribution across the entire stem cross-section, indicate that heat velocity underestimation may be more than in the woody species.

When the heat pulse technique is used to measure the transpirational flux in herbaceous plants, the direct computation of sap velocity from heat velocity is not feasible because the required values of the specific heat, bulk density, and water content of the conducting tissues are unavailable. Locating the conductive tissues and taking undisturbed samples of them to measure their physical properties is extremely difficult, because of the small size of the stems. However, it can be assumed that the cross-sectional area of conducting tissue and its properties for a particular plant specimen are constant. If this assumption is correct, calibration should show that transpiration is directly proportional to heat velocity. Cohen et al. (1988) have shown that this proportionality exists in cotton, but also that it depends only on the stem diameter. More precisely, the calibration factor is directly proportional to the stem's cross-sectional area.

The lack of information on the thermal properties of plant stems combined with an unknown conductive area requires repeated calibration for each herbaceous species. Even so, the validity of the method rests on the empirical function which relates the calibration factor to the total crosssectional area of the stem.

The objectives of this paper were to show the differences in calibration procedure between trees and herbaceous plants, and to discuss the problems encountered with application of the heat pulse method in new species.

\section{Measurement in trees}

The convective velocity $(v)$ of heat pulse from a heating wire radially inserted in a large stem is expressed as:

$v=\left(r^{2}-4 k t_{m}\right)^{1 / 2} / t_{m}$

where $r$ is the distance between the heating wire and the temperature sensor, $k$ is the thermal diffusivity of the wet wood, and $t_{m}$ is the time elap- sed between pulse emission and the occurrence of the maximum temperature, at the location of the temperature sensor. With known physical and thermal properties of the wood, the measurement of $t_{m}$ allows the computation of the sap flux density $J_{1}$ from:

$J_{l}=\rho \mathrm{cv} /\left(\rho_{l} \mathrm{c}_{l}\right)$,

where $\rho_{1}$ and $c_{1}$ are the density and specific heat of the liquid phase, respectively, and $\rho$ and $c$ are those of wet wood. These properties were measured once on several trees (Cohen et al., 1981); the average value was taken and assumed constant.

The thermal diffusivity $k$ is determined when no convective heat transport is taking place, i.e., $v=0$, so that:

$k=r^{2} /\left(4 t_{m}\right)$.

Sap flow becomes very low or ceases towards the end of the night, as experimentally verified by Cohen et al., 1981. Measurement of $t_{m}$ at that time can be used in Eq. [3]. Repeated measurements of $k$ in several trees (Cohen et al., 1981, 1985) have shown that this property is fairly constant for a given species, and that the influence of the observed variability on the determination of $v$ is small, except when $v$ is very low.

A 3-mm-diam probe, made of an epoxy compound and bearing six thermistors $10 \mathrm{~mm}$ apart, is inserted radially in the trunk $15 \mathrm{~mm}$ downstream of a heating wire. Each thermistor monitors the temperature change caused by the heat pulse. An electronic clock records the individual $t_{m}$ of each thermistor to determine the sap velocity distribution with depth below the cortex, using Eq. [1] and [2]. The circumferential distribution was established by inserting probes in three orientations per trunk. The average represents the sap velocity in the six concentric, $10-\mathrm{mm}$ wide annuli below the cortex. The sap flow is obtained by summing the product of each sap velocity multiplied by the area of the corresponding annulus.

A field calibration was carried out on two large 16 -yr-old citrus trees planted in weighing lysimeters (Green \& Brower, 1979), with black polyethylene sheets covering the soil surface to prevent evaporation. A laboratory calibration was performed on uniform sections of large branches of forest trees (Cohen et al., 1981).

\section{Measurements in herbaceous plants}

In herbaceous plants, thermal coupling to ambient temperature fluctuations disturbs the temperature wave caused by the heat pulse. Consequently, Eq. [1] does not apply. The eva- 
luation of the thermal diffusivity of stems is also difficult, due to uncertainty of obtaining zero flow. To overcome these difficulties, Closs (1958) suggested using a differential temperature measurement at two asymmetrically located points above and below the heat source. In this case the convective velocity $v$ is given as:

$v=\left(x_{1}-x_{2}\right) / 2 t_{0}$

where $x_{1}$ and $x_{2}$ are the distances directly above and below the line heat source, respectively, and $t_{0}$ is the time required for the temperature difference between $x_{1}$ and $x_{2}$ to return to its initial value. The sap velocity, $J_{l}$, is proportional to $v$, as given in Eq. [2], but because the procedure for obtaining undisturbed samples of conducting tissue from herbaceous stems has not yet been developed, the proportionality factor is unknown, but assumed to be constant. The calibration was carried out on potted cotton plants by simultaneously measuring the heat velocity in the stem, and the transpiration determined by weighing the pot to the nearest $100 \mathrm{mg}$ at 10 -min intervals (Cohen et al., 1988).

\section{Results and discussion}

The field and laboratory calibrations in large woody trunks show that the heat pulse method underestimates the sap velocity by nearly $45 \%$ (Table I). This proportion is almost constant for different species, regardless of the calibration procedure. By comparison, Swanson \& Whitfield (1981) computed that the $2.4-\mathrm{mm}$ diam stainless steel sensor used by Marshall (1958) underestimated the sap velocity by $60 \%$. Considering the differences in size and material used in our probes, this result is quite similar to our experimental findings.

In view of the uniformity of the calibration factors in different species and the agreement with the values derived from a numerical model, the discrepancy between theoretical and measured sap velocity seems to be species-independent. In a study with the kiwifruit vine, transpirational flux was successfully measured without a calibration, on the basis of the numerical correction (Edwards \& Warwick, 1984).

We suspect, however, that in some cases the underestimation may be species-dependent. Figure 1 provides indirect evidence that the calibration factor for palm trees is different from that found so far for the other trees. It presents the diurnal course of sap flow in six trees which received different amounts of irrigation water as measured with the heat pulse method using the calibration factor of 0.55 established for several trees (Table I). The curves follow very closely the normal diurnal evolution of atmospheric evaporative demand and illustrate both the responsiveness and the precision of the technique. Three trees were irrigated daily with $600 \mathrm{~L}$ each, which corresponds to 1.2 times the evaporation measured in a standard evaporation pan. The other three trees received half the amount. The daily transpiration in the first group, calculated from the heat velocity measurement, is $220 \mathrm{~L}$ per tree. The same calculation for the second group yields $150 \mathrm{~L}$ per tree. The relative difference is less than that of the irrigation application, indicating that the wet treatment exceeds the water uptake

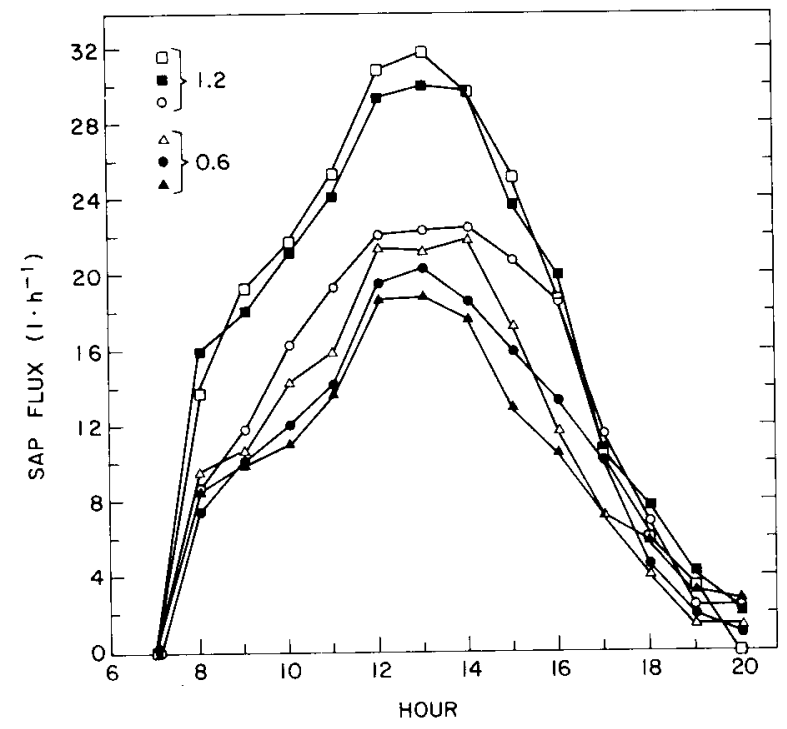

Fig. 1. Diurnal course of sap flow in palm trees. The daily irrigation of three trees corresponds to 1.2 or 0.6 times the evaporation measured in a Class A pan. 18 May 1986.

Table I. Ratio of measured-to-actual sap flux in four species, using different calibration procedures. 
capability of the trees, whereas the supply of the dry treatment is below the requirement. Consequently, the daily supply of $300 \mathrm{~L}$ in the dry treatment is mostly taken up by the trees, with evaporation from the soil being minimum through the use of drip irrigation. Although the estimate of water uptake by the palm trees is very approximative, the discrepancy between it (i.e. 300 L/day) and the result of the heat pulse measurement (i.e. $150 \mathrm{~L}$ day) is large enough to conclude that the 0.55 calibration factor is incorrect. This is not surprising in view of the peculiar vascular system of the palm tree (Sperry, 1986).

An example of the relationship between transpiration rate and convective heat velocity in the stem of a cotton plant is shown in Fig. 2. The data were collected every $10 \mathrm{~min}$ for a large and a small cotton plant from early morning to noon. The relationship for each plant is linear, but each plant has its own line. The lines meet at the origin of the axes. The slope of the linear regression is the proportionality factor between transpiration and heat velocity. It has the dimensions of area. The proportionality factor increases with stem cross-section. Figures 3 and 4 show a similar relationship between transpiration rate and heat velocity in soybean and corn. Low heat velocities in corn prevent the use of the method at low transpiration rates.

In contrast to the linear relationship found for cotton, soybean, and corn, the measured convective heat velocity of tomato plants is not proportional to the transpiration rate (Fig. 5). The curve suggests that the number of conducting elements in the stem increases with increasing transpirational flux. In this case the assumption

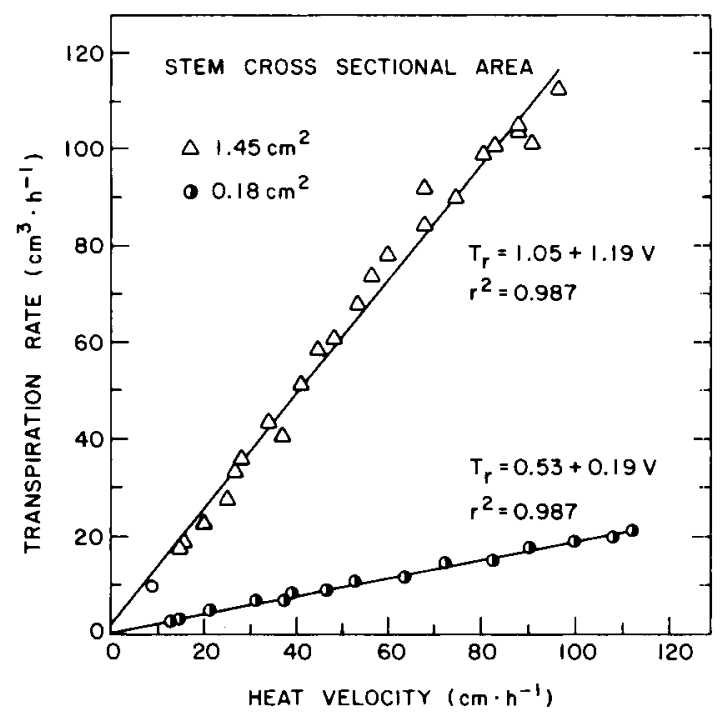

Fig. 2. Relationship between transpiration rate (Tr) of a cotton plant and the convective heat velocity (v), for two stems of different cross-sectional areas.

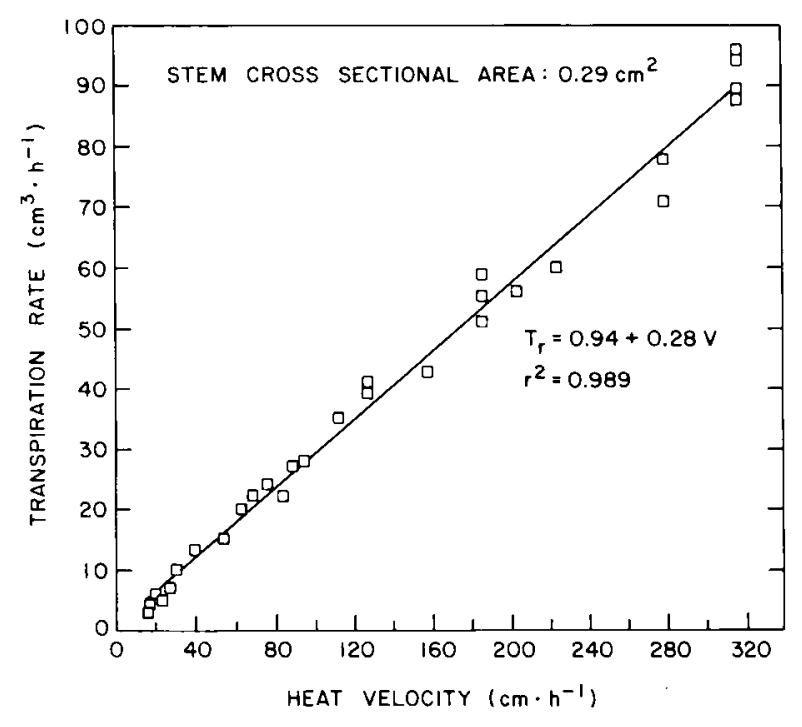

Fig. 3. Relationship between transpiration rate of a soybean plant and the convective heat velocity.

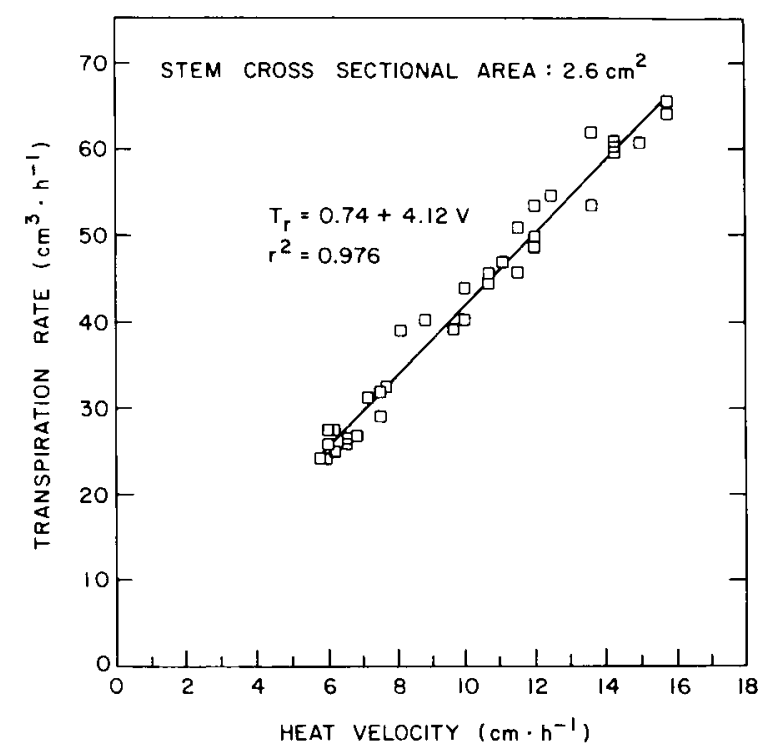

Fig. 4. Relationship between transpiration rate of a corn plant and convective heat velocity.

that the conducting tissue is a constant proportion of the total stem area seems incorrect. Therefore, the estimation of transpirational flux from measurement of heat velocity becomes problematic.

The proportionality factors found for 26 cotton plants and 18 soybean plants of different stem dimensions are highly correlated to stem crosssectional area at the level of probe insertion (Fig. 6). The slopes of the linear regressions may be considered as the constant factor to convert the product of convective heat velocity by stem area into transpirational flux. The value of the factor is different for the two species. Insufficient data kept us from carrying out a similar analysis for corn, but it appears that the factor will be close to 1.5. Differences between the species are to be 


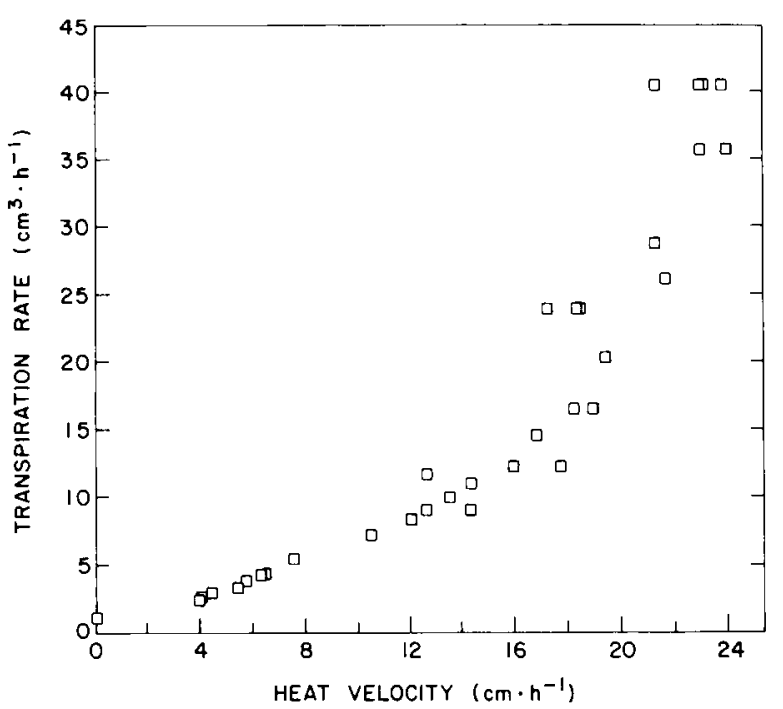

Fig. 5. Relationship between transpiration rate of a tomato plant and convective heat velocity.

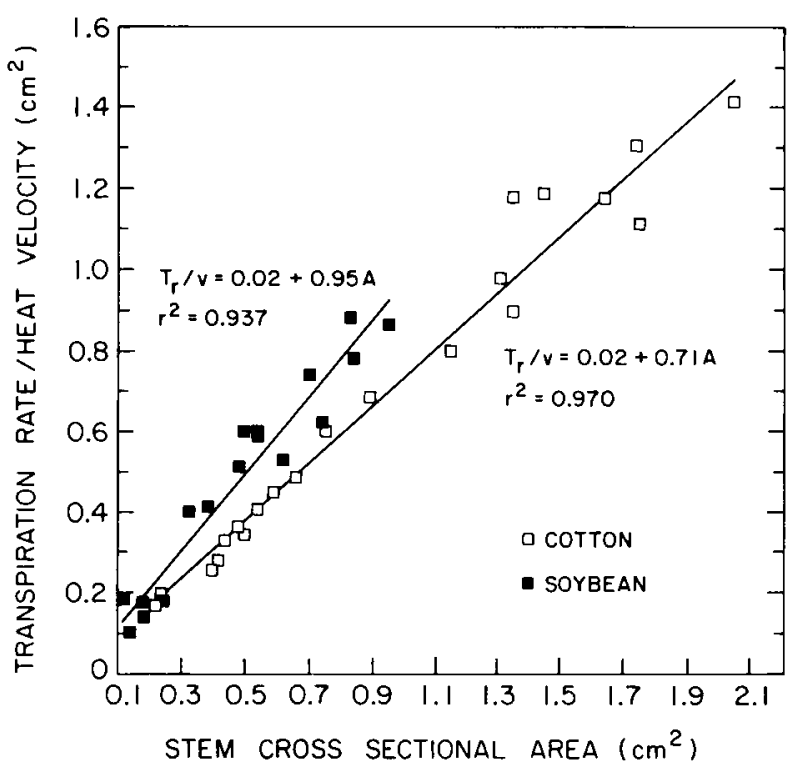

Fig. 6. The proportionality factor between transpiration rate (Tr) and convective heat velocity (v) shown in relation to the stem cross-sectional area (A) of 26 cotton and 18 soybean plants.

expected because their physical properties, wich affect the relation between heat and sap velocity, are dissimilar. A second reason is the assumption that the conducting tissue is proportional to total stem area, but the proportion varies bet- ween species. A third reason, which may explain the extremely low values of heat velocity found in corn, is a heterogeneous distribution of conducting vessels in the stem.

The heat pulse method can provide reliable measurements of water uptake. In tress, where physical properties of the trunk and conducting area can be measured, a numerical model or an empirical calibration can be used to compute the transpirational flux. In herbaceous plants, calibration is derived from measurements in a series of plants with different stem cross-sectional area. The calibration factor is a function of stem properties, which vary between species.

\section{Acknowledgement}

The work on palm trees was part of a project on palm irrigation made in cooperation with Dr. Oded Reuveni, Institute of Horticulture, ARO.

\section{References}

Closs R.L. (1958) The heat pulse method for measuring rate of sap flow in a plant stem. N. Z. J. Sci. 1, 281-288

Cohen Y., Fuchs M. \& Green G.L. (1981) Improvement of the heat pulse method for determining sap flow in trees. Plant Cell Environ. 4, 391-397

Cohen Y., Black T.A. \& Kelliher F.M. (1985) Determination of sap flow in Douglas-fir trees using the heat pulse technique. Can. J. For. Res. 15, 422-428

Cohen Y., Fuchs M., Falkenflug V. \& Moreshet S. (1988) Calibrated heat pulse method for determining water uptake in cotton. Agron. J. 80, (in press)

Edwards W.R.N. \& Warwick N.W.M. (1984) Transpiration from a Kiwifruit vine as estimated by the heat pulse technique and the Penman-Monteith equation. N. Z. J. Agric. Res. 27, 537-543

Green G.C. \& Brower W. (1979) An improved weighing lysimeter facility for citrus evapotranspiration studies. Water S. Afr. 5, 189-195

Marshall D.C. (1958) Measurement of sap flow in conifers by heat transport. Plant Physiol. 33, 385-396

Spery J.S. (1986) Relationship of xylem embolism to xylem pressure potential, stomatal closure, and shoot morphology in the palus Rhapis excelsa. Plant Physiol. $80,110-116$

Swanson R.H. \& Whitfield W.A. (1981) A numerical analysis of heat pulse velocity therory and practice. $J$. Exp. Bot. 32, 221-239 